\title{
IPTEKS PROSEDUR PEMBAYARAN PAJAK KENDARAAN BERMOTOR YANG TERUTANG PADA BADAN PENGELOLA PAJAK DAN RETRIBUSI DAERAH PROVINSI SULUT
}

\author{
Alma Meita Makausi ${ }^{1}$, Hendra Wati Bukidz ${ }^{2}$, Harijanto Sabijono ${ }^{3}$ \\ ${ }^{1,2,3}$ Jurusan Akuntansi, Fakultas Ekonomi dan Bisnis Universitas Sam Ratulangi, Jl. Kampus Unsrat, Manado, \\ 95115, Indonesia \\ E-mail : meytamakausi@yahoo.com
}

\begin{abstract}
This study aims to find out about taxes and how the application of payment procedures and imposition of motor vehicle tax penalties that have passed the maturity of the Tax and Retribution Management Agency in North Sulawesi Provinci Based on estabilished local government provisions and regulations, where existing procedures can make it easier to oblige tax in carrying out payments so that the procedure runs well. Texpayers are expected to be able to comply with existing procedures and provisions, so that there is no delay in paying taxes. Taxes that are local revenue are also expected to be able to improve the regional development structure of North Sulawesi,so that regional government development plans can be realized.
\end{abstract}

Keywords: Vehicle Tax,Payment Procedure,Tax Payable

\section{PENDAHULUAN}

Badan Pengelola Pajak dan Retribusi Daerah Provinsi Sulawesi Utara merupakan pendapatan asli daerah. Untuk peningkatan kualitas pembangunan. sehingga diperlukan penyesuaian atas peraturan daerah provinsi Sulawesi utara dibidang pajak kendaraan bermotor dengan menyesuaikan ketetapan undang-undang yang berlaku, sebagai salah satu bentuk upaya pemerintah dalam pembiayaan pembangunan daerah. Pajak ialah iuran rakyat yang dikelolah oleh Negara dan diatur oleh undang-undang yang diwajibkan dengan tiada mengaharapakan pengembalian langsung, karena pajak yang diperoleh untuk membayar biaya yang dikeluarkan pada daerah. Perlu diketahui juga karena pajak yang harus dibayarkan sesuai ketentuan yang berlaku, sehingga tidak dapat dihindari maupun di tolak karena merupakan suatu keharusan dalam melunasi pajak sebelum batas waktu yang telah tercantum.

Berdasarkan undang-undang di tetapkan peraturan pemerintah daerah provinsi Sulawesi utara. Pajak kendaraan bermotor merupakan pajak daerah yang hasilnya terbilang besar karena jumlah kendaraan yang cukup banyak, sehingga pemerintah harus memilik dan menerapkan prosedur dengan jelas agar lebih mudah dipahami oleh masyarakat. Sehingga wajib pajak dapat proses bayar pajak dengan tertib dan mengurangi kendala masyakarat sehingga memahami petunjuk dalam membayar pajak yang sudah lewat jatuh tempo. Walaupun begitu keberhasilan penerapan prosedur dalam aspek tersebut diharapkan mampu memberikan pelayanan yang baik bagi masyarakat secara akurat.

\section{TINJAUAN PUSTAKA}

Prosedur Pembayaran. Prosedur yang dijalankan oleh Dinas Pendapatan Pajak Daerah Provinsi Sulawesi Utara membantu mempermudah masyarakat dalam mengikuti peraturan ketika melewati batas bayar berdasarkan ketentuan UU perpajakan. Wajib Pajak yang terlambat membayar pajak kendaraan bermotor atau yang telah lewat masa jatuh tempo wajib melakukan pembayaran berdasarkan prosedur yang telah ditetapkan oleh pemerintah daerah. Wajib Pajak yang sudah lewat jatuh tempo pembayaran terlalu lama 
diberikan surat pemberitahuan oleh Dinas Pendapatan Daerah. Adapun prosedur pembayaran pada Dispenda yang harus dipatuhi jika yang sudah lewat jatuh tempo pembayaran sebagai berikut : STNK asli, KTP asli yang masih berlaku sesuai nama di STNK dan BPKB, Buka Blokir, dan melakukan pembayaran.

Sarana dan Prasarana dan/atau Fasiltias. Ada beberapa fasilitas yang disediakan oleh pihak Dispenda antara lain :

1. Ruang Pelayanan

2. Banner/Leaflet

3. Antrian Elektronik

4. Komputer

5. Meja

6. Kursi

7. Halaman Parker Roda 2 (dua) dan Roda 4 (empat)

8. Toilet biasa dan Toilet khusus disabilitas

9. Tangga Landai bagi penyandang cacat

10. Jaringan wifi

11. Televisi

12. Ruang baca

13. Smoking area

\section{METODE DAN TEKNIK PENERAPAN IPTEKS}

\subsection{Metode Penerapan Ipteks}

Metode ipteks yang diterapkan adalah Prosedur Pembayaran Pajak Kendaraan Bermotor berdasarkan kebijakan pemerintah daerah.

\subsection{Teknik Penerapan Ipteks}

Teknik penerapan ipteks yang dipakai adalah penerapan prosedur pembayaran pajak kendaraan bermotor melalui 3 langkah pembayaran : menyiapkan Stnk Kendaraan yang asli, KTP asli yang masih aktif di pakai dalam STNK dan BPKB, buka blokir, dan melakukan pembayaran.

\section{PEMBAHASAN}

\subsection{Gambaran Objek Penerapan Ipteks}

Dengan berkembangnya organisasi pada saat itu, sehingga membuat Kantor Inspeksi Pajak mengalami perubahan dengan nama instansi Dinas dengan nama Dinas Pajak dan Pendapatan di tahun 1984. Dengan beberapa kali terjadi perombakan nama instansi sebagai Dispenda Provinsi Sulawesi Utara.

\subsection{Pembahasan}

Prosedur pembayaran Wajib Pajak pada Pajak Kendaraan Bermotor yang terutang atau telah lewat masa jatuh tempo melalui 4 tahap prosedur yaitu mengenai :

1. STNK asli. Dalam melakukan pembayaran Pajak kendaraan Bermotor terutang melalui prosedur yang telah ditetapkan oleh Pemerintah Daerah harus membawa STNK asli sesuai dengan nama yang tecantum dalam KTP.

2. KTP asli yang aktif di pakai dalam STNK dan BPKB. Wajib Pajak Yang akan melakukan Pembayaran diharapkan membawa KTP asli yang masih aktif dipakai disesuaikan dengan nama yang terdaftar di STNK agar mempermudah dalam memproses data yang bersangkutan dalam pembayaran Pajak Kendaran Bermotor.

3. Buka Blokir. Setelah melengkapi berkas persyaratan pembayaran Pajak Kendaraan Bermotor yang telah di minta,maka pemblokiran Pajak kendaraan bermotor akan terbuka dan sudah bisa dibayar beserta denda atas sanksi yang telah ditetapkan oleh Peraturan Pemerintah daerah. 
4. Melakukan Pembayaran. Pajak jatuh tempo di sampaikan melalui SPT tahunan yang di kenakan denda dan terhitung sejak tanggal kesepakatan akhir yang telah disetujui sesuai ketentuan tanggal pembayaran. Wajib Pajak yang baru membayar pajak lewat dari masa jatuh tempo wajib membayar bunga pajak $2 \%$ dari jumlah pajak yang terutang.

\section{KESIMPULAN DAN SARAN}

\subsection{Kesimpulan}

Prosedur pembayaran pajak pada kendaraan bermotor bila terutang dapat terlaksana dengan baik jika prosedur yang telah ditetapkan oleh Perintah Daerah dapat diterapkan dengan lancar dan dipahami oleh Wajib pajak.

\subsection{Saran}

Pemerintah Daerah Provinsi Sulawesi Utara dapat lebih memperjelas prosedur pembayaran Pajak Kendaraan Bermotor dan menerapkannya dalam mempermudah wajib pajak untuk melakukan pembayaran sesuai dengan ketentuan yang ditetapkan sehingga berjalannya prosedur pembayaran dapat terlaksana dan berjalan dengan baik.

\section{DAFTAR PUSTAKA}

Faisal Reza Nasution, Abdul Muthalin (2017), Publikauma: Jurnal Administrasi Publik universitas Medan Area.

Husen Abdul ABDUL GHONI (2012), Jurnal Akuntansi UNES, Pengaruh Motivasi dan Pengetahuan Wajib Pajak Daerah.

Mardiasmo, 2011. Perpajakan, Penerbit - Edisi Revisi 2011, Andi : Yogyakarta.

Yeyen Epriyanti (2014), Prosedur Pembayaran Pajak Kendaraan Bermotor Pertahunan, http;//www.researchgate.net/publication/325995653_PROSEDUR_PEMBAYARAN_PA JAK_KENDARAAN_BERMOTOR_PERTAHUNAN

Surya Adi Praja (2017), Pelaksanaan Standar Pelayanan Pajak Kendaraan Bermotor Dikantor Bersama Samsat Upt Kutai Kartanegara.

Prutu Aditya Pranata, Putu Ery setiawan (2015), E-Jurnal Akuntansi Universitas Udayana, Pengaruh Sanksi Perpajakan,Kualitas pelayanan dan Kewajiban Moral Pada Kepatuhan Wajib Pajak.

Anak Agung,Ayu Mirah Kencanawati (2013), Jurnal Bisnis dan Kewirausahaan,Pengaruh Kepemimpinan, Etos Kerja,Motivasi dan Disiplin Terhadap Kinerja Pegawai Kantor Pelayanan Pajak Madya Denpasar

Reza Arditia (2013), Jurnal Akuntansi Unuse,Analisis Kontribusi Dan Efektivitas Pajak Daerah Sebagai Sumber Pendapatan Asli Daerah Kota Surabaya

Afrizal Tahar, Willie Sandy (2016), Jurnal Akuntansi dan Investasi, Pengaruh persepsi wajib pajak atas pelayanan KPP, sanksi perpajakan dan pengetahuan atas penghasilan kena pajak terhadap kepatuhan wajib pajak

Djoko Muljono (2010), Panduan Brevet : Akuntansi pajak dan ketentuan umum perpajakan

Gendut Sakarno, Lia Nariwati (2007), Jurnal Neo-Bis, Kontribusi Kualitas Pelayanan Terhadap Kepuasan Pembayar Pajak

Winda Kemala (2016), Jurnal Online Mahasiswa (JOM), Pengaruh Kesadaran Pajak, Sikap Wajib Pajak dan Reformasi Administrasi Perpajakan Terhadap Kepatuhan wajib Pajak Kendaraan Bermotor 